\title{
Ciudad compacta, ciudad dispersa. Lenguaje y manipulación
en la comunicación gráfica arquitectónica comercial
}

\section{Compact city, sprawled city. Language and manipulation in commercial architectural graphic communication}

\section{Resumen}

Autores:

Arq. Enrique Ferreras-Cid enrique.ferreras@uisek.edu.ec PhD. Verónica Rosero-Añazco veronica.rosero.arq@uisek. edu.ec

Universidad Internacional SEK Ecuador

Ecuador a Imagen ha adquirido un papel predominante en el discurso arquitectonico, reduciendo el espacio a un objeto de consumo visual. La hegemonía ocularcentrista hoy en día constituye una base en la concepción arquitectónica y urbana. Así, la arquitectura, más que un espacio, es una imagen con lenguaje propio, susceptible de múltiples interpretaciones. Bajo este principio, ciertos valores se asocian de forma adulterada a elementos recurrentes, generando dinámicas de manipulación en su comunicación gráfica. Con estos antecedentes, se contrastan dos modelos urbanos: la ciudad compacta y la ciudad dispersa. Su intencionalidad simbólica es abordada en base a las categorías otorgadas a la "función y el signo en arquitectura", planteadas por Umberto Eco: funciones primarias (denotativas) y secundarias (connotativas). Estos conceptos se han aplicado en el análisis de la gráfica de dos revistas ecuatorianas, una de difusión especializada (Trama) y otra de difusión popular (El Portal). La contrastación de los valores hallados finalmente genera una discusión sobre el lenguaje gráfico, su ética, y sobre el papel de la gráfica de otras categorías de difusión de la arquitectura, como las revistas científicas o las 'Little magazines' de los años 1960-1970 como respuesta a la "sociedad del espectáculo" de aquella época.

Palabras clave: gráfica arquitectónica, ciudad compacta/dispersa, lenguaje, símbolo, Ecuador.

\section{Abstract:}

The image has acquired a predominant role in the architectural discourse, reducing the space to an object of visual consumption. The current ocularcentrism hegemony constitutes a base in the architectural and urban conception. Thus, architecture rather than a space, is an image with its own language, susceptible of multiple interpretations. Under this principle, certain values are associated in an adulterated way to recurrent elements, generating dynamics of manipulation in their graphic communication. With this background, two urban models are contrasted: the compact city and the sprawled city. The approach to its symbolic intentionality is based on the categories given to "function and sign in architecture", proposed by Umberto Eco: primary (denotative) and secondary (connotative) functions. These concepts have been applied in the analysis of the graphics of two Ecuadorian magazines, one of specialized diffusion (Trama) and one of popular diffusion (El Portal). The contrasting of the found values finally generates a discussion about the graphic language, its ethics, and the role of the graphics of other categories of architectural diffusion, such as the scientific magazines or the 'little magazines' of 1960's - 1970's in response to the "society of the spectacle" of that time.

Keywords: architectural graphics, compact city/sprawled city, language, symbol, Ecuador. 


\section{Introducción}

Con una fuerte carga visual, la arquitectura acoge cada vez con más fuerza las nuevas técnicas de representación y comunicación, con un predominio de la imagen como medio de transmisión de ideas, discursos, pero en especial, de estilos de vida y modelos urbanos. El predominio de lo visual propiciado por el contexto sociocultural ha influido en las últimas décadas significativamente, reduciendo la riqueza del espacio arquitectónico a un objeto de consumo visual.

Si bien la influencia de la vista podría considerarse como fundamental en la aprehensión de la arquitectura, nunca este ocularcentrismo había tenido tal supremacía en la concepción de la arquitectura y la ciudad. Aunque ciertas maneras de entender la arquitectura, encabezadas por la corriente fenomenológica, han reaccionado a esas arquitecturas retinianas (Pallasmaa, 1996), es indudable la hegemonía de lo visual en la comunicación arquitectónica.

En este contexto de reflexión sobre la representación gráfica y predominio de lo visual se plantea la observación y contrastación de dos modelos urbanos: la ciudad compacta y la ciudad dispersa, focalizando los casos de estudio en Ecuador, contraponiendo dos publicaciones de relevancia nacional: la revista especializada Trama, y El Portal Inmobiliario, revista que hasta hace pocos años era el mayor canal de difusión en el panorama inmobiliario local (hoy trasladada a las redes sociales). Estos dos modelos de ciudad están sujetos también al proceso de autonomización de la imagen a través de una gráfica especializada, con valores que se asocian de forma perversa y adulterada a elementos recurrentes, generando dinámicas de manipulación en el consumidor visual.

Por tanto, no se transmite arquitectura en sí: más que un espacio, es una imagen con lenguaje propio, susceptible de múltiples interpretaciones que más allá del caso de estudio representan una constante en la cultura arquitectónica visual contemporánea.

\section{Discurso, hegemonía y símbolo de la imagen}

\subsection{La imagen como discurso}

La última mitad del siglo XX se caracterizó por un intempestuoso desarrollo tecnológico de la mano de la revolución digital. Este nuevo paradigma derivó inevitablemente en drásticos cambios sociales que convergen en la sociedad de la información. Este fenómeno, sumado a una creciente globalización, ha generado una infoxicación, es decir, una sobrecarga informativa de cara a la toma de decisiones, cuya principal consecuencia es la sustitución de referencias culturales por una cultura de lo visual. Esta cultura es susceptible de interpretación y engloba todas las realidades visuales, adquiriendo un papel cada vez más relevante en nuestra sociedad y en los espacios habitados.

La estrecha relación entre publicidad y arquitectura tiene su origen alrededor de la década de 1950, época en la que las imágenes se convirtieron en la nueva arquitectura (Colomina, 2006), "el decorado inclasificado donde pasamos nuestras vidas" (Smithson y Smithson, 2003 (1956)). Esto representa una transformación fundamental de la condición urbana con respecto a los cincuenta años anteriores. Los Smithson encontraron en las imágenes un método para determinar el estatus no solo de la arquitectura, sino de la sociedad, a través de sus investigaciones sobre la sociedad del consumo, la prefabricación y estandarización constructivas.

La imponente y creciente presencia del televisor en los hogares produjo progresivamente un aumento en el flujo de imágenes que empezaron a constituir el entorno de manera inconsciente en el espectador. La arquitectura se había convertido en parte de esas imágenes, realzando la domesticidad y la vida privada. La interpretación de estos espacios no podía realizarse aisladamente de los pequeños elementos que los configuraban: desde los muebles, los electrodomésticos, e incluso los atuendos y poses de quienes los habitaban, todos eran factores clave para su interpretación. Como un bucle, esas imágenes eran también una especie de edificio, habitadas igual que cualquier otro espacio arquitectónico.

Este fenómeno se puede observar a través de la producción del fotógrafo de arquitectura, Julius Shulman, quien cambió los paradigmas de la representación del espacio a través de sus fotografías premeditadas y maquinadas al detalle, en especial con respecto al estilo de vida en el interior de la casa suburbana, en una época donde el modelo de la dispersión urbana tomaba cada vez más fuerza.

A partir de entonces, los arquitectos entendieron que el ejercicio de la profesión tenía una serie de connotaciones y significados completamente diferentes a los de la generación previa. Las imágenes se convirtieron en la materia prima de su trabajo. Se redefinió así el papel de la arquitectura, situándola dentro de una nueva cultura de consumo.

Con una consolidación paulatina de la cultura televisiva y publicitaria, más adelante, Guy Debord (1967) enunció que las relaciones sociales están siendo mediatizadas por la imagen: lo que antes era vivido directamente, hoy se aprehende indirectamente a través de una representación.

En la misma línea, Baudrillard (1987) explica cómo lo visual sustituye a la realidad, y la hiperrealidad generada a través de mecanismos virtuales, reemplaza a la propia arquitectura. 


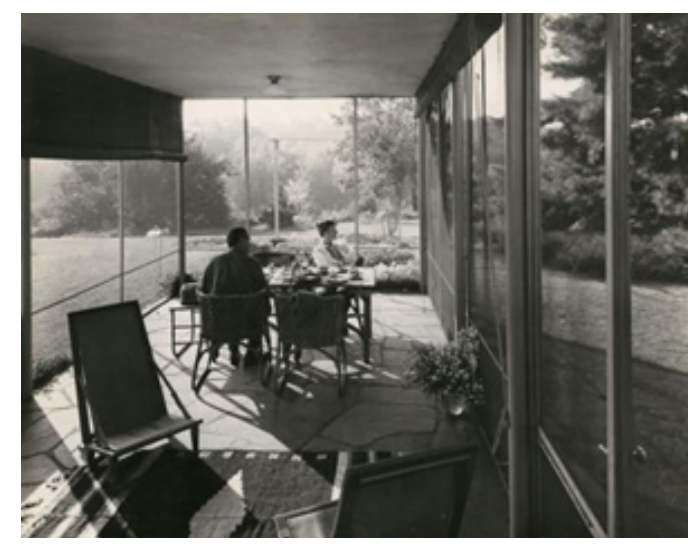

Figura 1: Damora. M. (1937). Walter Gropius desayunando en su casa en Lincoln, Massachusetts. La domesticidad como estrategia de promoción en el siglo XX [Fotografía]. Recuperado del archivo de Marcel Breuer.

En la década de 1990 se produce un auge digital que transforma los procesos productivos y comunicativos de manera mucho más acusada en las artes y disciplinas alográficas $^{1}$. La imagen tiene cada vez un papel más relevante en la manera de "comunicar" arquitectura: los recursos tecnológicos permiten generar espacios ficticios, de modo que se facilita enormemente la forma de adquirir información visual.

Por tanto, la imagen, ya sea generada digital o fotográficamente, es el paradigma de comunicación arquitectónica en el siglo XXI, donde "la arquitectura, además, se encuentra comprometida en la compraventa de opinión ideológica, propaganda o publicidad, todo ello sobre el soporte mediático del territorio urbano, suburbano o rural." (Miranda,1999, p. 10). En definitiva, "lo que se ve ya no es lo que se tiene" (Koolhaas, 2011, p.13).

Éste es un proceso en el que la producción arquitectónica sigue involucrada de manera progresiva y cada vez más intensa. Cada imagen producida (foto, render, boceto) establece un discurso cuyo contenido difiere según el medio de comunicación y su enfoque, que puede ser académicoteórico, proyectual o publicitario-comercial. En el ámbito comercial aparece como inevitable la presencia de un halo de manipulación publicitaria que extiende su campo de acción más allá de lo doméstico, tomando a los distintos modelos de ciudad como herramienta de comunicación del estilo de vida ideal a vender.

${ }^{1}$ Leon Battista Alberti introduce el concepto de alografía en la arquitectura, separando la mera construcción del diseño. La arquitectura como disciplina alográfica es proyectada por un autor y materializada por otro.

Término utilizado por Luis Fernández Galiano (2016) para referirse a la sobreabundancia de imágenes en el panorama arquitectónico.

3 Según Martin Jay el ocularcentrismo es el privilegio de la visión a través de los otros sentidos. Este tema es desarrollado fundamentalmente en "En el imperio de la mirada: Foucault y la denigración de la visión en el pensamiento francés del siglo XX" (1986) y Ojos abatidos. La denigración de la visión en el pensamiento francés del siglo XX (2007).

\subsection{Predominio de lo visual}

Si bien en el ámbito académico se tiende a excluir el estudio de los medios de comunicación populares, no hay que desdeñar su esfera de influencia: el habitante promedio absorbe, de manera inconsciente, una serie de estilos de vida 'ideales' a través de las revistas populares de decoración o de venta inmobiliaria con un amplio tiraje y difusión.

La fatiga visual ${ }^{2}$ propiciada por el contexto sociocultural presente ha influido en las últimas décadas de manera significativa en la arquitectura, reduciendo la riqueza del espacio arquitectónico a una imagen. Si bien la vista siempre fue estimada como el sentido fundamental en la aprehensión de la arquitectura, el privilegio de la visión a través de los otros sentidos ${ }^{3}$, jamás había tenido una supremacía tal sobre cualquier otro aspecto, tanto sensible como inteligible, en la concepción del objeto arquitectónico.

Este ocularcentrismo referido a la arquitectura es utilizado por Juhani Pallasmaa en su libro Los ojos de la piel (1996), para referirse a la tendencia de privilegiar la vista frente a los demás sentidos en el proceso arquitectónico. Así, cita a René Descartes, quien consideraba la vista como "el más noble y universal de los sentidos" (Pallasmaa,1996, p.23).

Aunque ciertas maneras de entender la arquitectura, encabezadas por la corriente fenomenológica ${ }^{4}$, han reaccionado respecto a esas arquitecturas retinianas, como es el caso de Pallasmaa, es indudable que el campo arquitectónico (de manera especial el campo de la comunicación arquitectónica) sigue dominado por lo visual.

\subsection{Gráfica y símbolo}

Ernst Cassirer definió al ser humano, como un animal simbólico: la estructura mental humana se guía por una asociación de ideas que generan símbolos. Dichos símbolos nos permiten trascender las ideas concretas, generando pensamientos más complejos fruto de un proceso inteligible.

El hombre no vive en un universo puramente físico sino en un universo simbólico. Lengua, mito, arte y religión [...] son los diversos hilos que componen el tejido simbólico [...]. Cualquier progreso humano en el campo del pensamiento y de la experiencia refuerza este tejido [...]. La definición del hombre como animal racional no ha perdido nada de su valor [...] pero es fácil observar que esta definición es una parte del total. (Cassirer, 1948, pp. 47-49).

4 La fenomenología se enfoca en el estudio de los fenómenos tal como se presentan en la realidad y se experimentan a través de los sentidos. Las principales figuras del pensamiento relativas a esta corriente son Edmund Husserl, Martin Heidegger y Maurice Merleau-Ponty. En lo relativo a la arquitectura, inicia en la segunda mitad del siglo XX. Uno de los pioneros en el tema fue Steen Eiler Rasmunssen con su libro La experiencia de la arquitectura. Le suceden, siendo los exponentes principales Steven Holl, Peter Zumthor y Juhani Pallasmaa. El énfasis de su arquitectura reside en causar fuertes impresiones sensoriales a través de recursos como la luz, agua o texturas para generar emoción en el espectador. 
Cuando el componente simbólico es reemplazado por la imagen, se genera un "empobrecimiento de la capacidad de entender" (Sartori, 1998, pp. 45-48), de modo que lo visual invierte el proceso de lo sensible en inteligible: la imagen visual sustituye a la imagen mental. En ese proceso, la percepción del espacio arquitectónico se desvirtúa, sustituyéndose la aprehensión antroposensorial del espacio tridimensional por una representación bidimensional sin ninguna cualidad. La arquitectura pierde todo atributo no perceptible visualmente y queda reducida a una imagen.

La aparición de los nuevos medios digitales surgidos en los últimos años del siglo XX, han sido un agente clave para que la comunicación gráfica derive hacia la simulación virtual de la arquitectura.

Para el desarrollo de la intencionalidad simbólica en los modelos urbanos estudiados, se han tomado las categorías otorgadas a la "función y el signo en arquitectura", planteadas por Umberto Eco (1971). Estas funciones se en dividen primarias y secundarias. Mientras la primera se refiere a la denotación del objeto analizado, la segunda se refiere a las connotaciones de mismo . Como el mismo Eco apunta, es importante no tomar estas categorías como axiológicas (jerárquicas), donde la una es más importante que la otra; es el valor comunicativo, intencional o simbólico que se otorga a cada categoría lo que interesa.

Tras la categorización, se enfatiza en el hecho de que las funciones del significado no permanecen estáticas, en cuanto que no siempre la función primaria permanece estable y sus funciones secundarias varían. Para la compresión de las diferencias entre funciones primarias y secundarias, Eco expone el siguiente ejemplo:

Es el caso del ready made: un objeto de uso es elegido como objeto de contemplación, incluso para connotar irónicamente su anterior utilización. Es el caso del cómic ampliado de Lichtenstein: la imagen de la mujer que llora ya no denota mujer que llora-denota fragmento de cómic sino que connota, entre otras cosas, la imagen de una mujer que llora según la civilización del cómic (Eco, 1971, p. 31).

Esta conversión implica que la imagen se llena de nuevos significados que paralelamente incitan a "recuperar los significados y las connotaciones que ya funcionaban para el lector naif' a manera de una vasta operación pop (Eco, 1971, p. 32). Así, la lectura es intencional, y el uso de la gráfica arquitectónica es tendencioso.

La intencionalidad simbólica relacionada a los valores teóricos de la disciplina no deja de combinarse con los valores de estilo de vida que se ensalzaron en la segunda mitad del siglo XX. Esto sucede por la inevitable relación del contexto construido con los mass media, que amenaza con invadir incluso la arquitectura más estimada peligrando su calidad artística y sus valores secundarios más loables: "solo hay un mundo más alejado y ajeno a

\footnotetext{
${ }^{5}$ Según la RAE: Denotar: Significar objetivamente.

Connotar: Conllevar, además de su significado propio o específico, otro de tipo expresivo o apelativo.
}

esa [verdadera] arquitectura que el mundo tecnocrático, y ese mundo es el mundo artístico que los mass media manipulan y venden." (Miranda, 1999, p. 9).

\section{Ciudad compacta y ciudad dispersa en dos medios de difusión en Ecuador}

Una vez desarrollados los conceptos, se procede a su estudio en un contexto y medios específicos. Ecuador cuenta con la revista Trama, publicación especializada gran recupersión en el país desde 1977 hasta la actualidad, siendo el medio más relevante de difusión de la arquitectura en el país. Por otro lado, se ha tomado El Portal Inmobiliario, revista que hasta hace poco constituía un medio de difusión masiva de la producción inmobiliaria local en formato impreso, hoy trasladada a las redes sociales, aunque con la misma estrategia gráfica que en papel.

En medio del proceso de autonomización de la imagen, ciertos valores se han asociado de forma perversa y adulterada a elementos recurrentes, generando dinámicas de manipulación en la comunicación gráfica arquitectónica comercial. No obstante, la gráfica de las revistas especializadas también está estrechamente vinculada este proceso aunque su intencionalidad difiera. La contrastación entre el modelo compacto y el modelo disperso de ciudad demuestra el empleo de ciertas estrategias habituales en el proceso comunicativo.

\subsection{Intencionalidad simbólica y distorsión funcional}

En los casos de estudio se observan considerables metamorfosis en cuanto a las funciones primarias que En los casos de estudio se observan considerables metamorfosis en cuanto a las funciones primarias que se tornan en secundarias; es decir, lo denotativo pierde sentido ganando valor la connotación simbólica en relación a ciertos elementos. La distinción en cuanto a los dos modelos urbanos (ciudad compacta y ciudad dispersa) se torna evidente en cuanto a los elementos y las distintas funciones secundarias (connotativas) adquiridas. Por tanto, se observan los siguientes patrones recurrentes en la manipulación de la comunicación gráfica:

\section{Ciudad compacta:}

Parece increíble que el tamaño de un edificio por sí solo encarne un programa ideológico, con independencia de la voluntad de sus arquitectos (Koolhaas, 2011, p. 6).

En este modelo, la verticalidad (altura) es el elemento jerárquico en cuanto a imagen se refiere.

Esta idea más que comunicar la propia volumetría de carácter vertical implícita en la tipología característica de la ciudad compacta, pretende significar las vistas como 
objeto de consumo que otorga estatus adicional a la arquitectura. En ocasiones, esta idea de opulencia y ostentación se ve complementada con elementos singulares, como piscinas, decks, etc.; que pretenden otorgar una ilusión de exclusividad.

El segundo elemento destacable de consumo visual relativo a los modelos arquitectónicos de la ciudad compacta es la ubicación: se pretende comercializar con la "exclusividad" de formar parte del núcleo urbano. Sin embargo, la ubicación no se comunica en relación a la proximidad de usos (característica de este modelo urbano), sino que el elemento empleado para referirse al emplazamiento y posición es el skyline. De esta manera, el propio perfil urbano se objetualiza y pasa a ser objeto de consumo. Esta relación entre la esbeltez volumétrica (verticalidad) y el skyline genera implícitamente en el espectador una idea de cosmopolitismo, en ocasiones reforzada con una cierta concepción pseudo-futurista que exalta la originalidad y el movimiento, tratando de evocar una relación entre la arquitectura y el mundo urbano sofisticado.
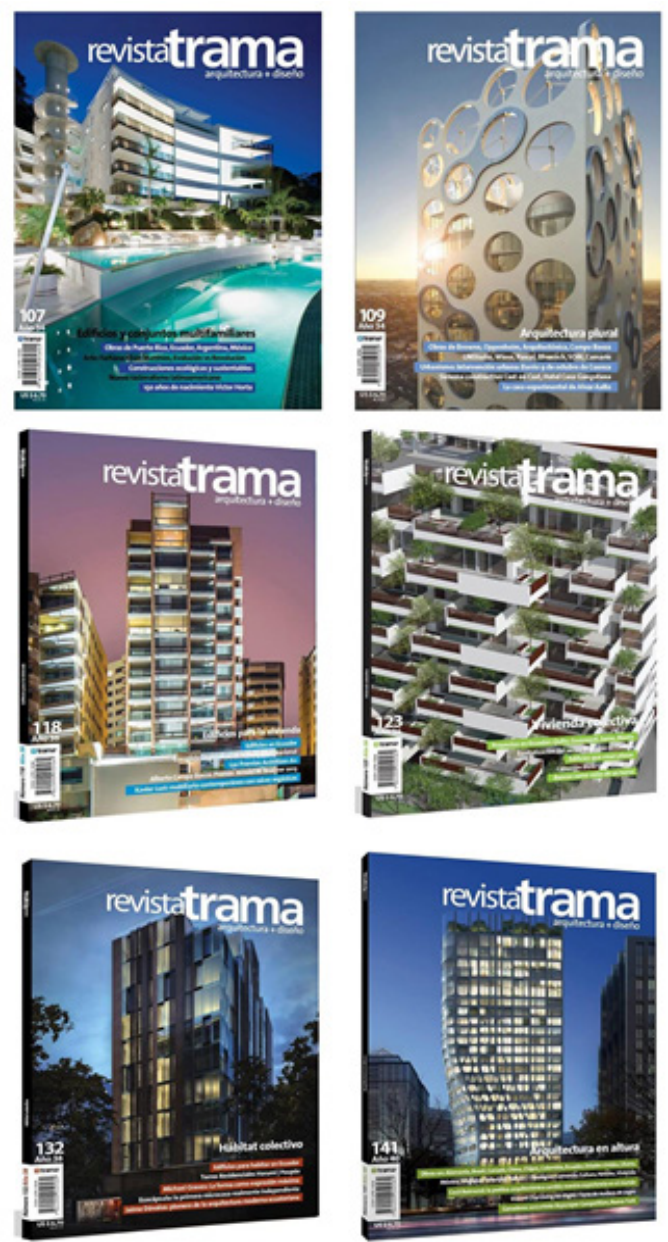

Figura 2: Collage de portadas de la revista Trama (no 107, 109, 118, 123, 132 y 141) [ Fotografía]. Recuperado de página web de la revista Trama
La mixtura funcional y proximidad de las mismas es ignorada, de la misma manera que la complejidad y posible riqueza social. El vehículo habitualmente no tiene un elevado protagonismo, puesto que si lo tuviera sería ciertamente contradictorio con este modelo urbano. Sin embargo, la lógica de la ciudad compacta sugiere un papel trascendente de las infraestructuras de carácter público, las cuales son ignoradas u omitidas en su totalidad: el transporte público no vende status.

Otra característica destacable en la gráfica comercial de la ciudad compacta es la iluminación nocturna como un recurso sistemático, provocando un "efecto pantalla" donde las fachadas del edificio no solo tienen un valor mercantil, espectacular y de comunicación connotativa, sino que pierden sus valores denotativos e incluso su necesidad de diálogo con el entorno.

Si podemos leer la historia de la arquitectura a través de la iluminación, observando cómo hemos pasado de la dependencia de la luz natural a la independencia que ofreció la iluminación artificial y cómo esta etapa resultó factor determinante para la configuración de la metrópoli que vive en tiempo continuo, ininterrumpido, cambiando de rostro y quizá de ritmo pero sin tener que asimilar la pausa o el reposo, como situación inevitable (Mantzou, 1999, pp. 49-50).

En definitiva, la gráfica relativa a la arquitectura de la ciudad compacta se enfoca al consumo sin realmente resaltar las cualidades urbanas de dicha forma de ciudad. La intención principal no es transmitir el hecho arquitectónico en cuanto a la función primaria se refiere (denotativa), ni tampoco los atributos de la ciudad compacta. El propósito fundamental es mercantilizar tanto el objzeto arquitectónico como la idea de ciudad compacta a través de la posición social, mediante la manipulación de los elementos anteriormente mencionados.

\section{- Ciudad dispersa:}

La manipulación en la comunicación gráfica arquitectónica en el modelo de ciudad dispersa está basado en la generación de una falsa relación con la naturaleza. Estos productos inmobiliarios no se ubican en un enclave natural, sino en núcleos urbanizados como condominios o urbanizaciones cerradas que impactan altamente en el territorio natural por su baja densidad. En el caso de la arquitectura del sprawl en las revistas especializadas, las obras escogidas rechazan modelos repetitivos. La casa aislada es producto de un encargo que en general denota singularidad, e incluso poder adquisitivo.

Uno de los elementos más explotados por la gráfica de la dispersión urbana es el césped, que se torna en un objeto de consumo, y sirve como nexo entre un elemento suburbano (la propia arquitectura) y una idea de natura, motivando esa falsa relación. Por otra parte se pretende suscitar de manera indirecta una (aparente) idea de tranquilidad, puesto que haciendo referencia a una relación con lo bucólico se procura evocar las virtudes de la vida campestre: tranquilidad, aire puro, naturaleza, seguridad.

El tema de la seguridad requiere especial puntualización de manera implícita, las revistas de difusión popular 
ofrecen publicidad complementaria sobre el contro compulsivo del espacio. Esto sugiere en los habitantes una cierta invulnerabilidad ante la criminalidad. Dichos habitantes han perdido la capacidad de identificar las fuentes reales de inseguridad en las ciudades y avalan un amurallamiento tácito (no mostrado en la publicidad). El resultado es, como menciona Mike Davis (2001), el aumento brutal de la población reclusa, y la bunquerización de las zonas residenciales, modelos avalados por un gran consenso social.

Como parte intrínseca de su condición suburbana, el vehículo pasa a una posición jerárquica de primer orden, puesto que este modelo de ciudad es altamente dependiente de dicho medio de transporte. E protagonismo del automóvil trasciende lo meramente operativo para dotar a la arquitectura de un valor agregado de status y comodidad.
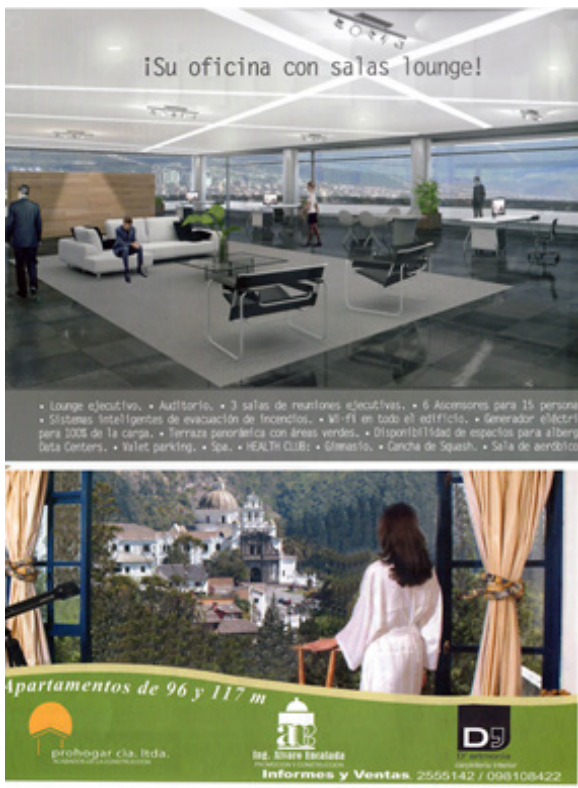

Figura 3: La vista como objeto de consumo [Imagen] Recuperado de Revista El portal inmobiliario s.n., ago-oct $04.2014,2004$

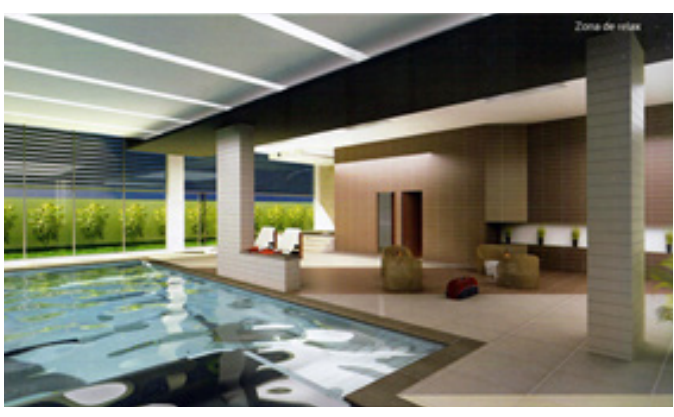

Figura 4: Render publicitario [Imagen]. (2014) Recuperado de Revista El portal inmobiliario, s.n.

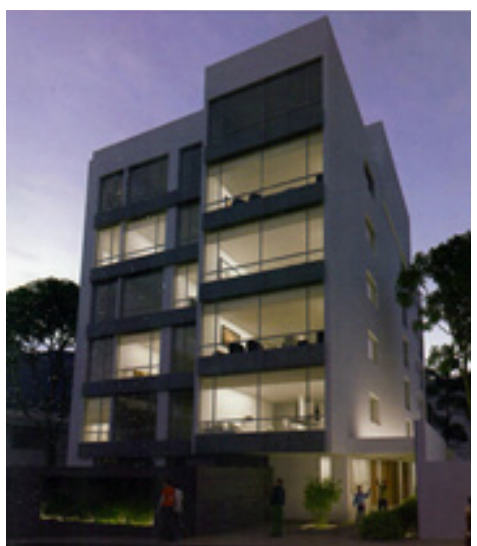

Figura 5: La iluminación nocturna como estrategia Render publicitario [Imagen]. Revista. (2014). Recuperado de El portal inmobiliario, s.n
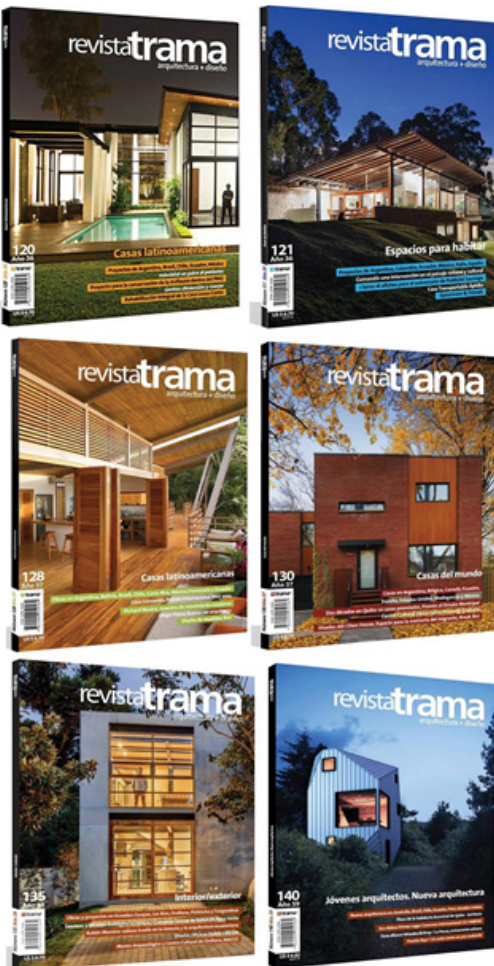

Figura 6: Collage de portadas de la revista Trama (n $120,121,128,130,135$ y 140) [Imagen]. Recuperado de página web de la revista Trama.

Las referencias al núcleo familiar tradicional constituyen también un elemento primordial en la comunicación inmobiliaria. Las escenas familiares son recurrentes, tratando de evocar de manera implícita una (simulada) idea de felicidad doméstica: la arquitectura se vuelve un objeto representacional, resultado de unas necesidades programáticas estereotipadas. Esta utilización del ideograma de familia tradicional contribuye adicionalmente a la perpetuación de los roles de género. 
Por otra parte, la vivienda individual pero repetitiva, habitualmente se complementa con una serie de áreas y espacios comunales (piscinas, canchas, juegos infantiles...) que adquieren una elevada jerarquía en cuanto a comunicación visual. De esta manera, a la vez que se otorga exclusividad, se pretende solucionar el problema del aislamiento de los conjuntos residencialespuesto que el modelo de ciudad dispersa presenta una segregación de usos muy acusada dificultando el acceso a una variedad y libertad de dichos usos, condiciones que sí posee la ciudad compacta.

La manipulación gráfica de los modelos suburbanos busca ocultar una realidad en la que el condominio residencial no reemplaza a la ciudad en cuanto a compacidad complejidad y diversidad. Esta ficción pretende rechazar el aislamiento urbano que en numerosas ocasiones convierte a estos conjuntos residenciales en islas independientes monofuncionales, cuyo panorama espacial y sobre todo social se vuelve pobre y monótono, generando una ausencia de vida pública informal. ${ }^{6}$

En resumen, en el caso de la ciudad compacta, su gráfica comercial pretende transmitir un estilo de vida urbano sofisticado y cosmopolita, empleando símbolos relacionados con la ubicación (cercanía), el estatus (lujo) y la altura (vistas).

Si se observa la gráfica comercial de la ciudad dispersa, se detecta fácilmente cómo la comunicación de sus valores se centra en la tradición y la familia, así como elementos relacionados con la naturaleza, donde incluso, como comenta Colomina (2006), el césped se vuelve un objeto más de consumo. Paralelamente, el automóvil se vuelve un elemento jerárquico, debido a una ubicación aislada de los núcleos urbanos que transmite una aparente tranquilidad y protección, lejos del ruido urbano.

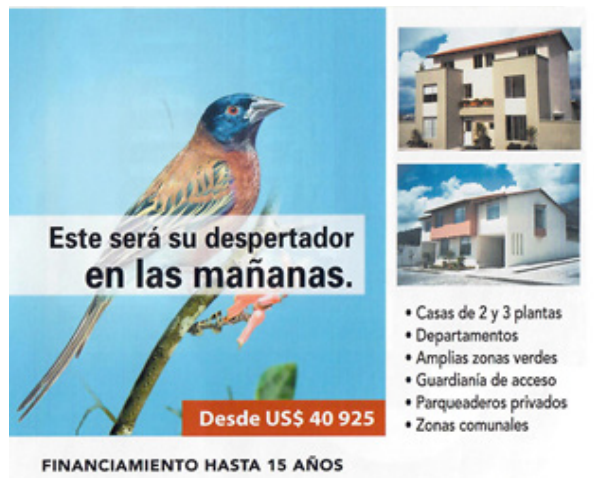

Figura 7: Manipulación sobre la presencia de la naturaleza. Publicidad inmobiliaria [Imagen]. Recuperado de Revista El portal inmobiliario, no ago.- oct 04. 2004.

\footnotetext{
6 Según Ray Oldenburg (1999), una de las principales consecuencias derivadas del problema del lugar surgido en la modernidad es la ausencia de vida pública informal, la cual es sustituida por la familia, el trabajo y el consumo.
}

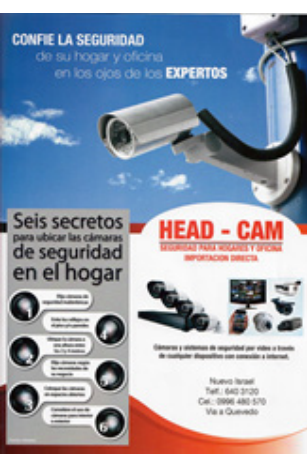

Figura 8: Nociones de seguridad Imagen publicitaria [Imagen]. Recuperado de Revista El portal inmobiliario, no ago-oct04. 2016.

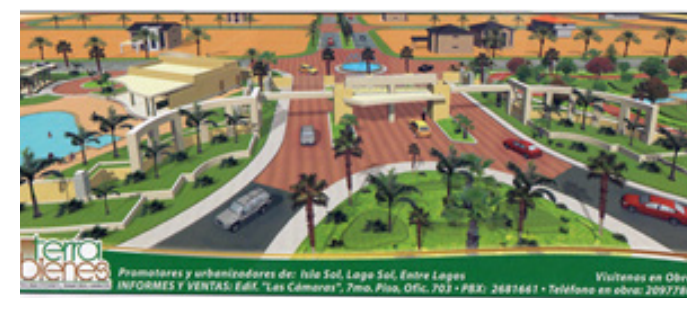

Figura 9: El auto como elemento jerárquico en la ciudad dispersa [Imagen]. Recuperado de Revista El portal inmobiliario, no dic03-feb04. 2004.

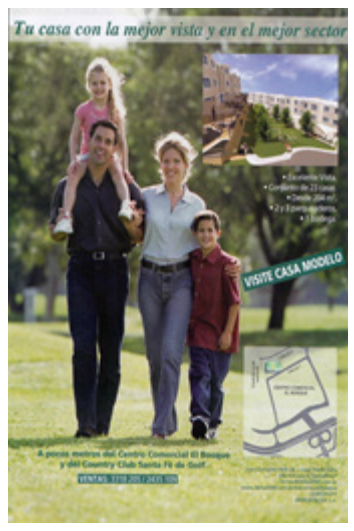

Figura 10: La familia como recurso de venta [Imagen]. Recuperado de Revista El portal inmobiliario, no may-ago 04.2004

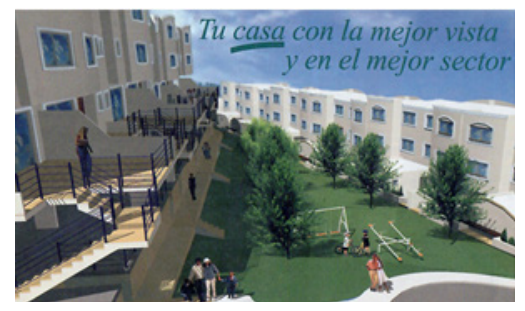

Figura 11: Áreas comunales de la publicidad inmobiliaria [Imagen]. Recuperado de Revista El portal inmobiliario, no mar-may 04.2004. 


\section{Discusión. Imagen discurso: categorización de la relación entre el enfoque gráfico y el consumidor (visual)}

La lectura de las funciones primarias y secundarias del objeto permite, a través del análisis de los casos de estudio, observar que la distorsión de la función primaria vs secundaria es menor en una revista de difusión especializada de la arquitectura, en donde el objeto arquitectónico aparece de manera más objetiva si se compara con los medios de difusión popular. Esto significa que la intencionalidad simbólica en medios especializados, la manipulación gráfica con respecto a un estilo de vida específico, es más sutil: mientras la gráfica comercial ha reemplazado por completo las funciones denotativas por las connotativas, la gráfica especializada oscila entre sus valores primarios y secundarios, donde, sin perderse lo denotativo, lo connotativo adquiere potencia por su carga teórica.

Los casos de estudio tienen por objeto, además de su teorización y análisis, la reflexión y debate sobre el uso de la gráfica arquitectónica en los medios de difusión que, como se ha observado, han reemplazado sus valores primarios por unos secundarios. Este reemplazo no siempre es positivo, en especial si lo asociamos a la gráfica comercial, que manipula la percepción de consumidor visual, mediante una ficción que prima sobre la realidad.

Esto no es más que el reflejo de una sociedad inmersa en coyunturas globales de consumo acelerado, sin tiempo y capacidad de asimilación y menos aún de reflexión. Esta es una situación de crisis a la que el mundo ha debido adaptarse y sobre la cual se viene reflexionando durante varias décadas, es especial en la década de 1960 cuando Debord escribía sobre la sociedad del espectáculo.

También la ansiedad de la llegada del nuevo milenio produjo profundas reflexiones sobre la forzada adaptación a lo mediático:

La adaptación parece trasladarse del nivel de la operación arquitectónica a la propia ciudad o incluso a un nivel más general, manifestando que la "crisis de lo urbano" remite a una crisis más amplia de representación de la contemporaneidad. El tema de la representación hace sumergir la identidad herida en la ficcionalización de nuestro mundo (Mantzou, 1999, p. 50)

Los mass media han incorporado nuevos mensajes, y po lo tanto nuevas lecturas en el espacio arquitectónico y urbano, transformando su naturaleza a través de medios de comunicación masivos. Su existencia produce de forma indefectible la necesidad de una postura contrapuesta que paradójicamente también usa como herramienta los medios de comunicación. Este fue el caso de la arquitectura radical de las "pequeñas revistas" (Little magazines) de los años 1960 y 1970 (Colomina, 2010), distribuidas impresas, aprovechando el auge en aquel entonces de las nuevas tecnologías de impresión a bajo costo.

Este estudio ha puntualizado en el análisis de dos categorías de medios de comunicación, uno especializado y otro de difusión popular. No obstante, caben dos categorías adicionales. Precisamente esas denominadas "pequeñas revistas" surgieron como un espíritu contestatario e incluso progresista, y eran movilizadas por críticos de la arquitectura (como Denise Scott-Brown ${ }^{7}$ ) en respuesta a los cambios políticos, sociales y artísticos de la época. Estas publicaciones (autodefinidas como pequeñas revistas, transformándose en "meta" pequeñas revistas) no solo representaban arquitectura, sino que eran espacios de producción arquitectónica en sí, constituidas como un locus primario de experimentación y debate (Colomina, 2010, p. 8) que desafiaba el status quo mediante seductoras imágenes y sugerentes contenidos.

En ellas la imagen ya no era solo imagen: era un metalenguaje:

En la década de 1970 se produce un cambio significativo [... en las formas de expresión del individuo contemporáneo. E minimalismo desarrollado a finales de los sesenta da paso, casi imperceptiblemente, a nuevas instrumentalizaciones a la hora de expresarse, ya sean artistas, escritores, arquitectos, filósofos, ingenieros... La utilización de la imagen gráfica por diferentes medios y soportes, viene a significar un cambio sustancial en la capacidad para establecer nuevos lenguajes con los que expresar las ideas (Barba, 2007, p. 25).

No es una coincidencia que la producción de estas "pequeñas revistas" haya surgido contemporáneamente a una crisis de la educación arquitectónica. Sus páginas testificaban que la pedagogía era un tema central y de preocupación internacional (con inquietudes no muy lejanas a las del momento actual), por lo que sus contenidos fueron clave en la reforma de identidades y objetivos de las escuelas de arquitectura. Paralelamente, muchas de las revistas mostraron posturas políticas progresistas que presentaron nuevas aproximaciones a la crítica histórica e ideológica sobre el rol de la arquitectura del capitalismo.

A la luz de la discusión académica, aparece una cuarta categoría: las revistas académico-científicas, que presentan un nivel aún más alto de especialización, construidas en base a artículos de investigación, con mayor complejidad en sus contenidos y mayor profundidad de reflexión. Su gráfica en general es un medio para comprender o reforzar un discurso académico, más la imagen no es un discurso en sí (salvo si esa es su intención explícita). No obstante, su nivel de difusión es radicalmente menor $^{8}$ y su público más específico.

Se debe además prestar atención a las posibilidades ampliadas de algunos de estos medios gracias a los

\footnotetext{
Al respecto, ver por ejemplo las reflexiones realizadas en su texto "Learning from pop", publicado en The Journal of Popular Culture, 7(2), 387-401.
} 
canales de difusión electrónicos que les permiten tener soportes digitales que influyen en la repercusión de la aprehensión de su discurso y gráfica, además de ofrecer en algunos casos ciertos niveles de interactividad ${ }^{9}$.

En la discusión sobre la categorización entra aquello que el filósofo estudioso de la influencia de los medios de comunicación en los procesos sociales, Marshall McLuhan (1987), apuntaba sobre "el medio y el mensaje", insistiendo en que la comprensión de fenómenos mediáticos parte más que del análisis de contenidos, del análisis del medio en sí, otorgándole más peso a la significación del medio. En ese sentido, los canales de difusión de los contenidos añaden más carga simbólica a la ideología que construye el medio utilizado para transmitir el mensaje, influyendo así en el contenido de la comunicación, siendo este, además un reflejo del receptor de la información.

Así como en la crisis entre los años 1960-1970 y la proliferación de las nuevas técnicas de reproducción fueron factores definitorios en la generación de estas revistas contestatarias, las nuevas tecnologías también presentan interesantes posibilidades de nuevas propuestas, metalenguajes y personajes como los descritos en Clip Stamp Fold:

Estos arquitectos e investigadores renegados se comprometieron a reinventar la vivienda como sinécdoque ${ }^{10}$ de la Tierra, exhibiendo una convicción sin precedentes, [...] ideas que desde entonces se han trasladado de la periferia para convertirse en una parte del paradigma dominante. (Colomina, 2010, p. 11. T. del A.)

Los lenguajes de manipulación en la gráfica arquitectónica comercial encuentran empatía con esa época de radicalidad en las publicaciones. Estos patrones detectados en aquel período se replican de manera casi análoga en la actualidad con independencia de los medios tecnológicos. Las intencionalidades de ambas posturas son similares, aunque los medios y canales de difusión sean novedosos.

Ya existen revistas que rechazan la forma institucionalizada de contar la arquitectura, enfocada en comunicar la cultura de la visión: la visión desde el poder, desde el vouyerismo, desde la gente, desde las cloacas, desde la ciencia, sin distinciones entre lo banal y lo sublime (Barba, 2007).

Las posibilidades de los medios de comunicación contemporáneos y su uso intensivo de la imagen, permitirán que el ocularcentrismo actual y las funciones secundarias de la imagen sean canalizadas como instrumento de reconfiguración de los valores de la gráfica, hoy distorsionados, donde la arquitectura cabal tenga un compromiso de representación real y ético.

\footnotetext{
8 Aquí se citan tres ejemplos nacionales: mientras la revista $\mathrm{E}$ Portal Inmobiliario en su versión impresa tenía un tiraje de entre 10.000 y 20.000 ejemplares bimensuales y hoy un alcance mayor en medios digitales, la revista Trama distribuye 1.000 ejemplares bimensualmente y la revista ESTOA entre 300 y 500 ejemplares semestrales.
}
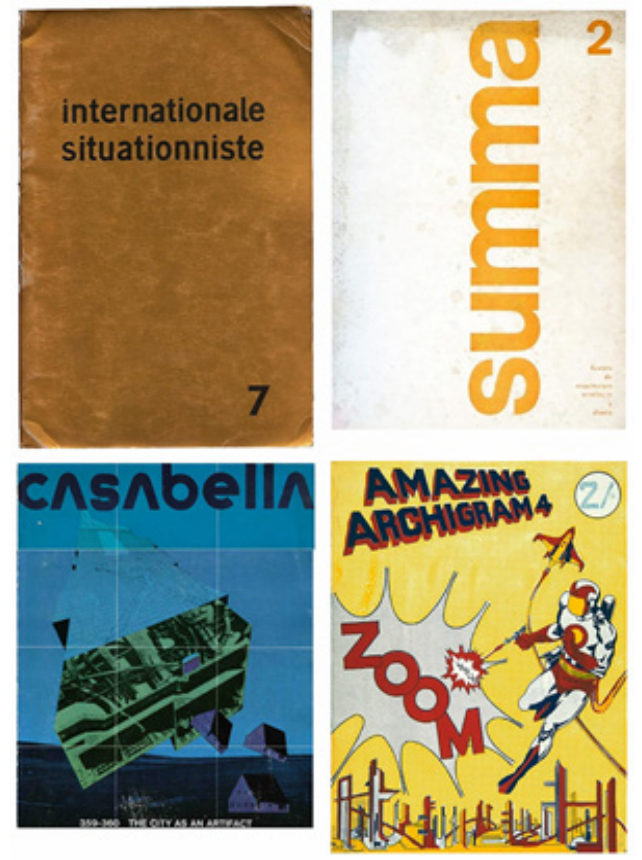

Figura 12: Collage "Little magazines" (1960-1970) [Imagen]. Recuperado de Clip Stamp Fold
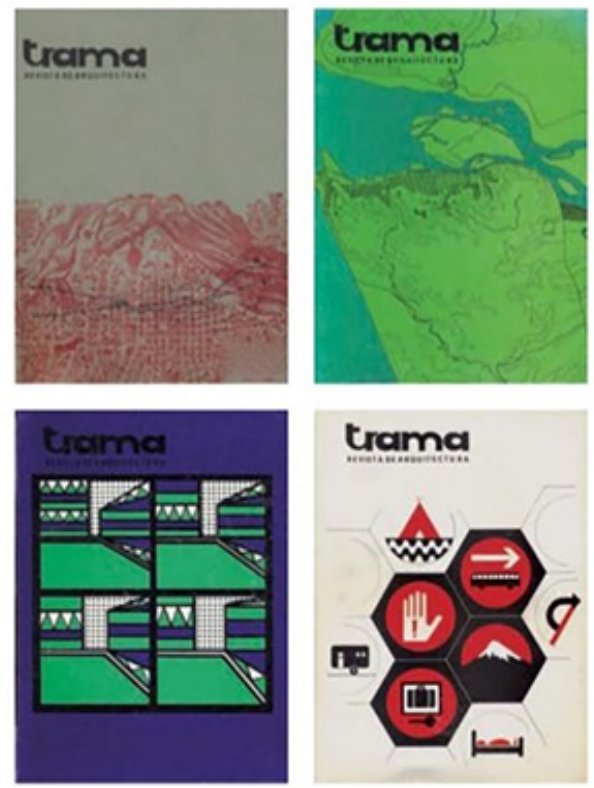

Figura 13: Collage primeras ediciones revista Trama, Ecuador [Imagen]. Recuperado de Revista Trama primera generación.

${ }^{9}$ El Portal se compagina con su difusión en Facebook; Trama no presenta formatos digitales abiertos; ESTOA se basa en el principio de la apertura del conocimiento con artículos especializados abiertos y gratuitos.

${ }^{10}$ Figura retórica de pensamiento que consiste en designar una cosa con el nombre de otra con la que existe una relación de inclusión. 


\section{Referencias bibliográficas}

- Barba, J. J. (2007). La arquitectura de la ciudad Con y Después del Lugar. METALOCUS. En L. Cirlot, Arte, arquitectura y sociedad digital (pp. 25-34). Barcelona, España: ESARQ-UIC.

- Baudrillard, J. (1987). Cultura y simulacro. Barcelona, España: Kairos.

- Cassirer, E. (1948). Saggio sull'uomo. Milán, Italia Longanesi.

- Colomina, B. (2006). La Domesticidad en Guerra Barcelona, España: Actar.

- Colomina, B. (2010). Clip Stamp Fold. The Radical Architecture of Little Magazines. Barcelona, España: Actar.

- Davis, M. (2001). Más allá de Blade Runner: Control urbano: la ecología del miedo. Barcelona, España: Virus.

- Debord, G. (1967). La sociedad del espectáculo. Barcelona, España: Pre-textos.

- Eco, U. (1971). La función y el signo en arquitectura: la comunicación arquitectónica y la historia. Cuadernos de Arquitectura y Urbanismo, (82), 30-33.

- Fernández Galiano, L. (2016). Quince tesis. Arquitectura Viva, (189), 17-50

- Jay, M. (1968). En el imperio de la mirada: Foucault y la denigración de la visión en el pensamiento francés de siglo XX. En M. Foucault, A critical Reader. Oxford: Basel Blackwell.
- Jay, M. (2007). Ojos abatidos. Madrid, España: Akal.

- Koolhaas, R. (2011). Grandeza, o el problema de la talla. Barcelona, España: Gustavo Gili.

- Mantzou, P. (1999). La arquitectura en la era de los media. Astrágalo. Arquitectura y mass media. Alcalá de Henares, España: Celeste Ediciones.

- McLuhan, M., Fiore, Q. y Agel, J. (1987). El medio es el mensaje. Barcelona, España: Paidós.

- Miranda, A. (1999). La arquitectura frente a la doxa. Astrágalo. Arquitectura y mass media. Alcalá de Henares, España: Celeste Ediciones.

- Oldenburg, R. (1999). The Great Good Place: Cafes, Coffee Shops, Bookstores, Bars, Hair Salons, and Other Hangouts at the Heart of a Community. Boston, EE.UU Da Capo Press.

- Pallasmaa, J. (1996). Los ojos de la piel. La arquitectura y los sentidos. Barcelona, España: Gustavo Gili.

- Sartori, G. (1998). Homo videns. La sociedad teledirigida. Buenos Aires, Argentina: Taurus.

- Smithson, A. y Smithson, P. (2003). But today we collect ads. Architecture d'adjourd'hui, 40-45. 